\title{
Ambulatory Arterial Stiffness Index Is Increased in Hypertensive Childhood Disease
}

\author{
GIACOMO D. SIMONETTI, RODO O. VON VIGIER, ELKE WÜHL, AND MARKUS G. MOHAUPT
}

\begin{abstract}
Division of Paediatric Nephrology [G.D.S., R.O.V.], Department of Nephrology and Hypertension [G.D.S., M.G.M.], University of Bern, 3010 Berne, Switzerland; Division of Paediatric Nephrology [E.W.], University of Heidelberg, 69120 Heidelberg, Germany
\end{abstract}

\begin{abstract}
Arterial hypertension in adults is often associated with an increased arterial stiffness, which correlates with the ambulatory arterial stiffness index (AASI) as derived from ambulatory blood pressure (BP) measurements. The purpose of this study was to demonstrate whether children with diagnosed hypertension have an increased AASI as in hypertensive adults. AASI was calculated from 185 ambulatory BP measurements of 114 hypertensive and 71 normotensive, healthy children. Hypertensive children had higher AASI values compared with their normotensive healthy counterparts $(0.370 \pm 0.120$ versus $0.204 \pm 0.199, p<0.0001)$. Children with longer duration of hypertension or a history of primary or secondary aortic coarctation displayed even more elevated AASI values. A receiver operator curve derived cut-off of AASI set at 0.301 distinguished $(p<0.0001)$ hypertensive from normotensive children with an odds ratio of 8.2 , a sensitivity of $81 \%$, and a specificity of $65 \%$. Moreover, AASI correlated with pulse and systolic BP. In conclusion, AASI is elevated in hypertensive children and correlates with the duration and the origin of hypertension in childhood. (Pediatr Res 64: 303-307, 2008)
\end{abstract}

$\mathrm{D}$ iseases linked to arterial hypertension are associated with a significant increased cardiovascular risk, either due to the primary disease (i.e. chronic kidney disease, obesity), or due to the effects of arterial hypertension on the cardiovascular system by consecutively damaging target organs such as the heart, the kidneys, and the brain (1). Increased left ventricular cardiac mass is an established marker of cardiovascular target organ involvement, but is only present in approximately $40 \%$ of children with hypertensive diseases (2). Additional and more sensitive noninvasive markers of hypertensive target organ damage are required to determine outcomes and to guide clinical and pharmacological management of childhood hypertension (3). Arterial stiffness, which is a strong predictor of cardiovascular complications and target organ damage in both the general population and patients with hypertensive diseases, would qualify as such a marker (4-7).

Most methods to measure arterial stiffness require special and expensive equipment and trained observers, often not available in clinical practice in a pediatric unit. A novel method to address arterial stiffness based on 24-h ambulatory

Received December 13, 2007; accepted April 18, 2008.

Correspondence: Markus G. Mohaupt, M.D., Division of Hypertension, Department of Nephrology and Hypertension, University of Bern, CH-3010 Berne, Switzerland; e-mail: markus.mohaupt@insel.ch

Supported by the Fondazione Ettore e Valeria Rossi (G.D.S.), the Swiss Renal Foundation (G.D.S., M.G.M.), and the Swiss National Foundation (Nr. 3200B0113902/1) (M.G.M.). blood pressure monitoring (ABPM) has been proposed (8): the ambulatory arterial stiffness index (AASI), defined as one minus the regression slope of diastolic over systolic blood pressure (BP) measurements obtained during a 24-h period. This ABPM-derived index has been shown to correlate with classical measures of arterial stiffness, such as pulse wave velocity (9), and to provide prognostic information on cardiovascular mortality and target organ damage throughout a wide age range, including young individuals $(10-12)$.

The purpose of this study was to demonstrate whether AASI is increased in children with various hypertensive diseases, as in hypertensive adults $(9-11)$.

\section{MATERIALS AND METHODS}

Patients. ABPMs performed at the University Children's Hospital of Berne and of Heidelberg between January 2003 and November 2006 were retrospectively reviewed. Children, aged 5-16 y, with hypertensive diseases were identified based on the formal diagnosis of arterial hypertension, as related to a given child's age, gender, and height $(1,13)$, by elevated 24-h ABPM values and/or antihypertensive treatment with a confirmed diagnosis of arterial hypertension. ABPMs of healthy children served as control (14). Untreated children were defined as being healthy in the absence of an acute or chronic illness and presenting with weight, height, BMI, and 24-h ABPM measurements within the 5 th -95 th percentile range. These healthy children were matched for age and gender with their hypertensive counterparts. In addition, a group of young hypertensive adults (WHO grade II-III) and a group of young healthy normotensive adults, recruited at the Department of Nephrology and Hypertension, University Hospital of Bern, served as controls.

All subjects without clinical necessity for 24-h ABPM, who served as controls, gave informed consent for ABPM as independently approved by the ethical review board of the Universities of Heidelberg and of Bern, Switzerland, for adults and for children.

BP measurement. Ambulatory BP was recorded in all individuals on an outpatient base using an oscillometric device (model 90207 Spacelabs Medical, Issaquah, WA, or model bp one, Cardiette, Cavareno, Italy) that was set to take a reading every 15-20 min during daytime and every 30-45 min during nighttime. The two devices were compared with a noninvasive BP analyzer (CuffLink, Dynatech, NV). The CuffLink includes options to perform a static pressure calibration. Cuff pressure oscillations simulating a range of BP levels and heart rates enabled comparisons of dynamic BP changes in both monitors. The measured pressures were comparable and the resulting computed AASIs were very well reproducible: AASI as provided by the CuffLink device of 0.250 , model bp one of 0.249 , model 90207 Spacelabs of 0.254 . This indicates a difference in the AASI between the two devices of up to a maximum of $2 \%$.

Ambulatory arterial stiffness index. Using the individual 24-h BP readings, diastolic was plotted against systolic BP and the linear regression slope was calculated with appropriate statistical software. The slope was not forced through the origin. AASI was defined as one minus the regression slope $(8,9)$. ABPM profiles were included for further analysis if a significant linear

Abbreviations: AASI, Ambulatory arterial stiffness index; ABPM, Ambulatory blood pressure monitoring; BP, Blood pressure; PP, Pulse pressure 
regression $(p<0.05), \geq 20$ readings per sampling period, and more than 18 continuous hours with valid readings were present.

Statistical analysis. Data are expressed as mean \pm SD. Relations among variables were assessed by using a best fit linear or logarithmic regression analysis, as appropriate. Mann-Whitney test was used to separately analyze the pediatric or the adult subgroups. Univariate linear regression analysis of AASI was performed with respect to age, gender, weight, height, and BMI in the individuals studied. A receiver operator curve was performed to set a cutoff for AASI as related to arterial hypertension. Odds ratio, sensitivity, and specificity were assessed with a Fisher's exact test. All statistical analyses were performed using Systat version 10 for Windows (Systat Software, San Jose, CA). Significance was assigned at $p<0.05$.

\section{RESULTS}

In the specified time frame, we identified 118 ABPMs of hypertensive children at our institutions, of which 114 (96.6\%) could be included for AASI computation (two measurements were excluded because the number of recordings was $<20$, and the other two were excluded because the derived linear regression to calculate AASI was not significant). The underlying diseases were essential hypertension in 14 children $(12.3 \%)$, primary or secondary coarctation of the aorta referred to as "cardiovascular disease" in 16 children (14\%, 14 with a surgically reconstructed coarctation of the aorta and two with a transposition of the great arteries with postoperative secondary aortic coarctation), and solely obesity-associated hypertension in three of six overweight children (2.7\%) (15). The largest group of children consisted of 81 children with renal diseases $(71 \%)$. Thirty-seven out of these $81(45.7 \%)$ children presented with moderate to severe renal insufficiency as indicated by a GFR of less than $60 \mathrm{~mL} / \mathrm{min} /$ $1.73 \mathrm{~m}$ (2) (chronic kidney disease stages 3-5). ABPMs of 73 healthy children were available for comparison (14), of which $71(97.3 \%)$ ABPMs could be evaluated (two measurements were excluded because the linear regression to calculate AASI was not significant). The main clinical characteristics of the studied children are depicted in Table 1.

Young adult patients with hypertension $(n=89)$ were randomly chosen from our database and 84 (94.4\%) could be evaluated (five measurements were excluded because the number of recordings was $<20$ ). Thirty-three individuals were female (39.3\%), the mean age was $32 \pm 4.5 \mathrm{y}$, and mean systolic and diastolic 24-h BP was $136.5 \pm 15.4$ and $87.3 \pm$ $10.5 \mathrm{~mm} \mathrm{Hg}$, respectively. Among these patients, the underlying disease was mostly essential hypertension (43 patients, $51.2 \%$ ), secondary hypertension due to renal disease of any chronic kidney disease stage (31 patients, $36.9 \%$ ), or endocrine disease (nine patients, $10.7 \%$ ); one patient (1.2\%) suffered from neurofibromatosis type 1 . Fourteen (16.7\%) hypertensive adults had moderate to severe renal insufficiency with a GFR of less than $60 \mathrm{~mL} / \mathrm{min} / 1.73 \mathrm{~m} \mathrm{(2)} \mathrm{(chronic} \mathrm{kidney}$ disease stages 3-5) and obesity was present in 19 patients (22.6\%). ABPMs of 61 young adult healthy normotensive volunteers were evaluated; among them 57 (93.4\%) could be assessed (three measurements were excluded because the number of recordings was $<20$, and the other one was excluded because the linear regression to calculate AASI was not significant). Twenty-eight individuals were female $(49.1 \%)$, the mean age was $27.1 \pm 5.8 \mathrm{y}$, and the mean
Table 1. Clinical characteristics of the children population

\begin{tabular}{|c|c|c|}
\hline Characteristics & $\begin{array}{l}\text { Healthy } \\
\text { children }\end{array}$ & $\begin{array}{l}\text { Hypertensive } \\
\text { children }\end{array}$ \\
\hline No. & 71 & 114 \\
\hline Female $(\%)$ & $35(49.3)$ & $52(45.6)$ \\
\hline Male $(\%)$ & $36(50.7)$ & $62(54.4)$ \\
\hline Age $(y)$ & $12.1 \pm 2$ & $12.0 \pm 3.6$ \\
\hline Weight (kg) & $41.1 \pm 12.5$ & $46.2 \pm 21.2$ \\
\hline SDS Weight—age & $-0.21 \pm 0.85$ & $0.18 \pm 1.1 *$ \\
\hline Height $(\mathrm{cm})$ & $149.5 \pm 13.6$ & $146.8 \pm 21.6$ \\
\hline SDS Height-age & $-0.11 \pm 0.75$ & $-0.41 \pm 1.19$ \\
\hline BMI $\left(\mathrm{kg} / \mathrm{m}^{2}\right)$ & $18 \pm 2.8$ & $20.6 \pm 4.5 \dagger$ \\
\hline SDS BMI-age & $-0.18 \pm 0.93$ & $0.61 \pm 0.96 \dagger$ \\
\hline Children with obesity (\%) & $0(0)$ & $6(5.3)$ \\
\hline $\begin{array}{l}\text { Chronic Kidney Disease Stages } \\
\quad 3-5(\%)\end{array}$ & $0(0)$ & $37(32.4) \dagger$ \\
\hline $\begin{array}{l}\text { 24-h Systolic Blood Pressure } \\
(\mathrm{mmHg})\end{array}$ & $109.5 \pm 7.6$ & $125.5 \pm 13.2 \dagger$ \\
\hline $\begin{array}{l}\text { 24-h Diastolic Blood Pressure } \\
\text { (mmHg) }\end{array}$ & $66.4 \pm 6.2$ & $77.9 \pm 11 \dagger$ \\
\hline $\begin{array}{l}\text { 24-h Mean Blood Pressure } \\
\text { (mmHg) }\end{array}$ & $80.7 \pm 6.2$ & $93.7 \pm 11.2 \dagger$ \\
\hline 24-h Pulse Pressure (mmHg) & $43.4 \pm 5.1$ & $47.6 \pm 7.9 \dagger$ \\
\hline $\begin{array}{l}\text { Night-time Mean Blood Pressure } \\
\text { Dipping }(\%)\end{array}$ & $17.6 \pm 6.4$ & $12.4 \pm 7.3 \dagger$ \\
\hline $\begin{array}{l}\text { Ambulatory Arterial Stiffness } \\
\text { Index (AASI) }\end{array}$ & $0.204 \pm 0.199$ & $0.370 \pm 0.120 \dagger$ \\
\hline
\end{tabular}

Data are mean $\pm \mathrm{SD}$.

$* p=0.01$ and $\dagger p<0.0001$ compared with the normotensive healthy children. Significance performed with a Mann Whitney test.

SDS, standard deviation score.

systolic and diastolic $24-\mathrm{h}$ BP was $111.5 \pm 6.9$ and $73.8 \pm 6.4$ $\mathrm{mm} \mathrm{Hg}$, respectively.

The children with various hypertensive diseases had higher AASI values than those with normotension $(0.370 \pm 0.120$ versus $0.204 \pm 0.199, p<0.0001$ ) (Fig. 1). The cumulative distribution curve of AASIs showed a shift to the right in both hypertensive children (Fig. 2A) and adults (Fig. 2B) compared with normotensive individuals, thus indicating an increased AASI due to hypertensive diseases. A cutoff set by the receiver operator curve for AASI at 0.301 for children distin-

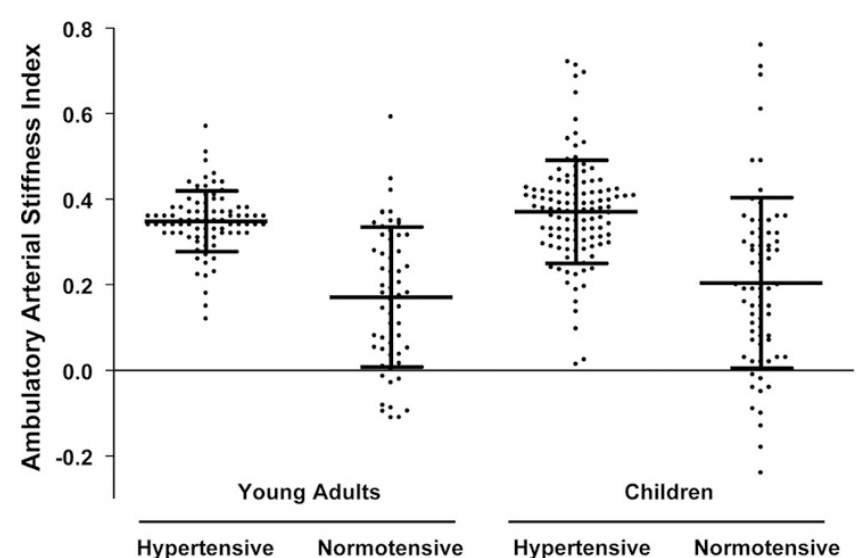

Figure 1. Ambulatory arterial stiffness index (AASI) in normotensive and hypertensive children and young adults. Individual data points represent one AASI calculation. Lines and bidirectional error bars indicate mean \pm SD. Hypertensive subjects of either age have a higher $(p<0.0001)$ AASI compared with their normotensive counterparts. Normotensive children and adults have similar AASI values. 
A

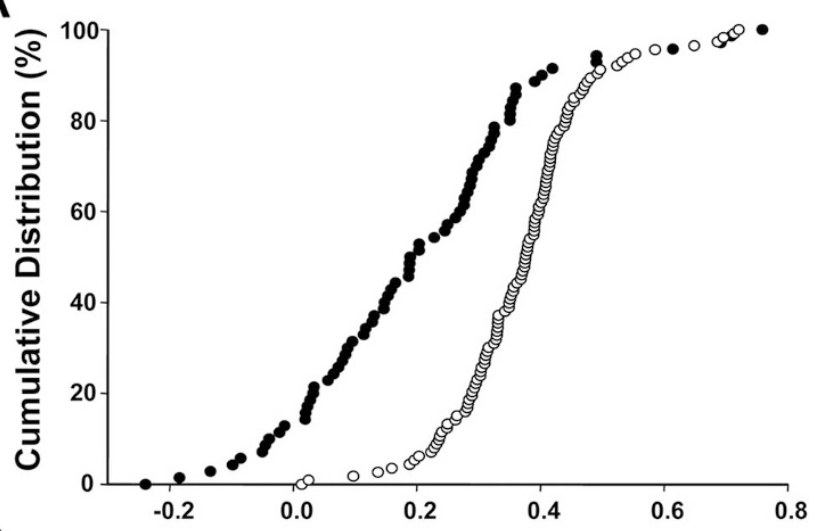

B

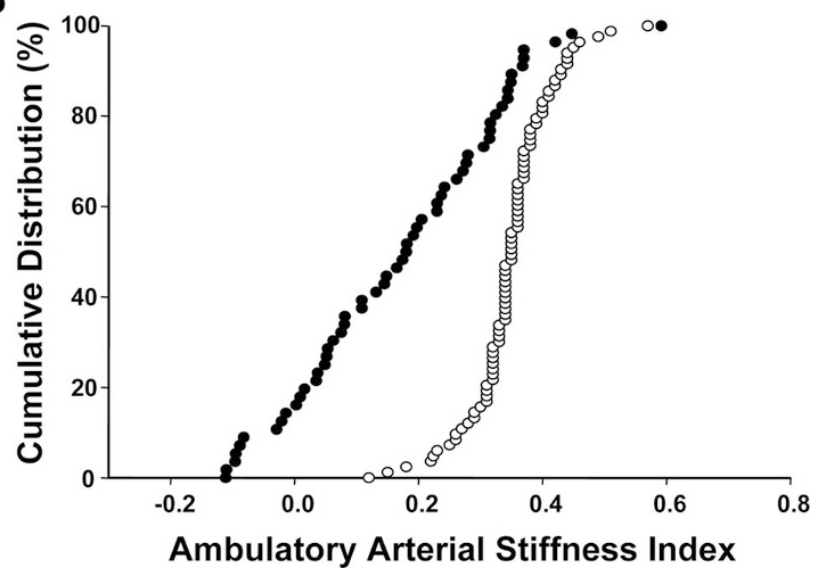

Figure 2. Cumulative distribution of the ambulatory arterial stiffness index (AASI) in normotensive $(\bullet)$ and hypertensive $(\bigcirc)$ children $(A)$ and adults $(B)$. Individual data points represent one AASI calculation.

guished $(p<0.0001)$ the hypertensive from normotensive children with an odds ratio of 8.2 (95\% CI 4.2-16.2), a sensitivity of $81 \%$ (95\% CI $73-88 \%$ ), and a specificity of $65 \%$ (95\% CI 54-76\%). Similarly, this cutoff also distinguished $(p<0.0001)$ the hypertensive from normotensive young adults with an odds ratio of 14 (95\% CI 6-32), a sensitivity of $82 \%$ (95\% CI $72-89 \%$ ), and a specificity of $76 \%$ (95\% CI 62-87\%).

Excluding the groups of children with cardiovascular disease and with essential hypertension, the children with hypertension due to renal diseases $(n=81)$ demonstrated higher AASI values than healthy children $(0.347 \pm 0.111$ versus $0.204 \pm 0.199, p<0.0001)$. When compared with the group of children with renal diseases, the smaller groups of children with cardiovascular diseases $(n=16,0.435 \pm 0.131$ versus $0.347 \pm 0.111, p=0.020$ ) and with essential or obesityassociated hypertension $(n=17,0.423 \pm 0.119$ versus $0.347 \pm 0.111, p=0.036$ ) had higher AASIs. The group with cardiovascular hypertensive diseases had higher AASIs when compared with all other hypertensive children $(0.435 \pm 0.131$ versus $0.360 \pm 0.116, p=0.041)$. These subgroups of hypertensive children did not significantly differ with respect to age, gender distribution, BP level, or age.

When the children with chronic kidney disease were divided according to the duration of the disease into group 1 (congenital disorders and/or duration of hypertension $>3 \mathrm{y}$,
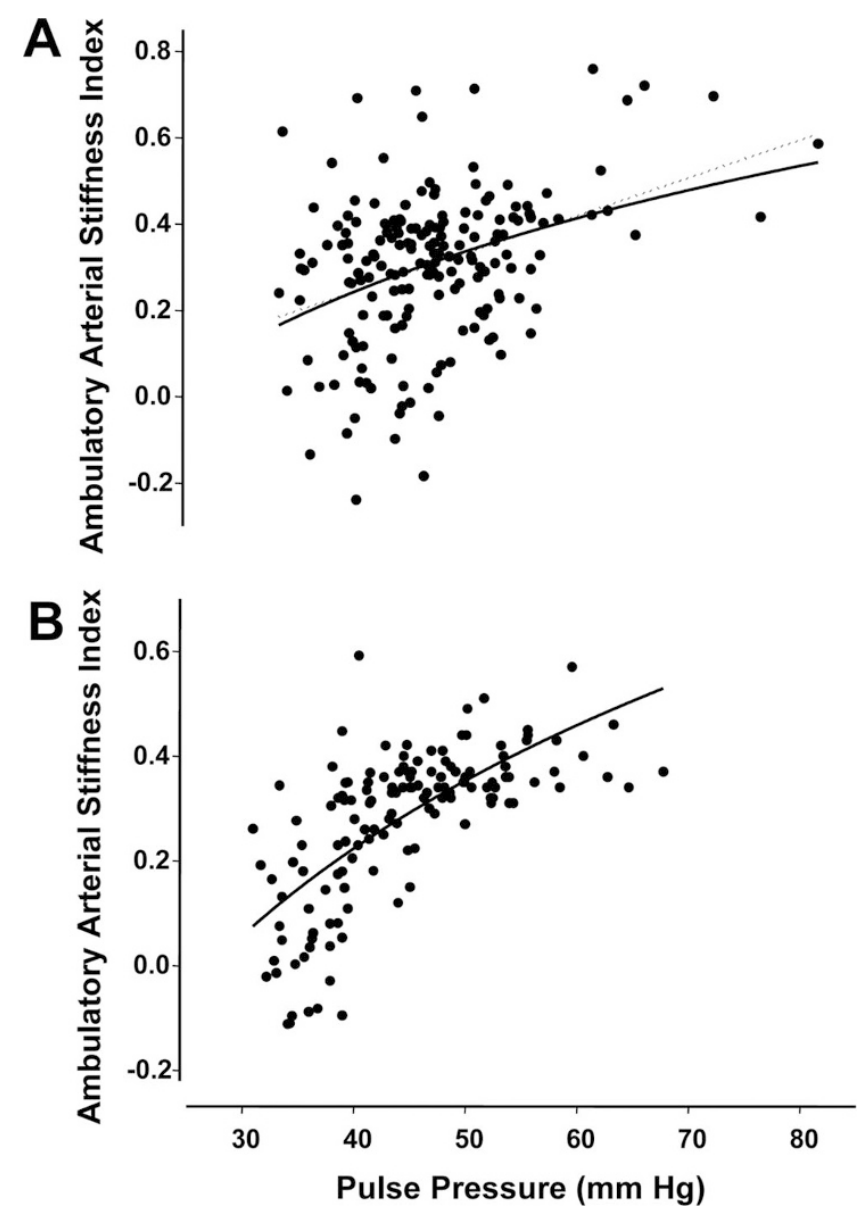

Figure 3. Correlation between ambulatory arterial stiffness index (AASI) and pulse pressure in all children $(A)$ and in all young adults $(B)$. Individual data points represent one AASI calculation. Logarithmic (solid line) and/or linear (dotted line) regressions are depicted for children (logarithmic: $r^{2}=$ $0.1340, p<0.0001$; linear: $r^{2}=0.1428, p<0.0001$ ) and adults (logarithmic: $\left.r^{2}=0.4603, p<0.0001\right)$.

$n=45$ ) or group 2 (duration $<3 \mathrm{y}, n=36$ ), a positive correlation was found between duration of the disease and AASI value $(0.378 \pm 0.106$ versus $0.311 \pm 0.109, p=0.014)$.

AASI showed modest but consistent increases with 24-h pulse pressure (PP) $\left(r^{2}=0.1340, p<0.0001\right.$; Fig. $\left.3 A\right)$ and 24-h systolic BP, as expressed in age-adjusted standard deviations $\left(r^{2}=0.0363, p=0.0096\right)$. We did not find a relation between AASI and 24-h diastolic BP when considering all children; however, analysis of hypertensive children only revealed an inverse correlation between AASI and 24-h diastolic BP $\left(r^{2}=0.09657, p=0.0008\right)$.

Hypertensive adults had significantly higher AASI than healthy normotensive adults $(0.348 \pm 0.071$ versus $0.171 \pm$ $0.163, p<0.0001$ ) (Fig. 1). In the adult population, AASI correlated with age $\left(r^{2}=0.1324, p=0.0054\right.$, only the healthy population considered), as well as 24-h PP $\left(r^{2}=0.4603, p<\right.$ 0.0001 , Fig. 3B), 24-h systolic $\left(r^{2}=0.2488, p<0.0001\right)$, and diastolic BP $\left(r^{2}=0.1111, p<0.0001\right)$.

In the healthy pediatric population, AASI did not correlate with age or other anthropometric data (weight, height, or BMI). We did not observe significant differences related to gender in healthy children (prepubertal and pubertal) or in the 
healthy adult population. However, a trend toward higher AASI values in male subjects was noticeable.

An inverse relationship between AASI and nocturnal dipping of mean arterial pressure was present in the pediatric and adult population $\left(r^{2}=0.1741, p<0.0001\right.$ and $r^{2}=0.2734$, $p<0.0001$, respectively). Moreover, dippers (defined as a nocturnal fall of mean $\mathrm{BP} \geq 10 \%$ ) had lower AASI values compared with nondippers: AASI of dipping $(n=138)$ versus AASI of nondipping $(n=47)$ children was $0.269 \pm 0.167$ versus $0.415 \pm 0.152$, respectively $(p<0.0001)$, and AASI of dipping $(n=98)$ versus AASI of nondipping adults $(n=43)$ was $0.257 \pm 0.143$ versus $0.321 \pm 0.144$, respectively $(p=$ 0.01). Computing AASI with individual BP daytime readings (AASI day) confirmed higher AASI levels in both groups of hypertensive individuals, children, as well as adults (data not shown).

\section{DISCUSSION}

Arterial stiffness, as determined by pulse wave velocity, is predictive of cardiovascular complications (16). Pulse wave velocity, relating changes in vessel diameter to distending pressure, and the analysis of pulse wave form represent the gold standards for the evaluation of arterial stiffness (17). However, these methods are rarely used to assess children because they are time consuming, require specific technical equipments, and are often displeasing; thus other indicators of an increased vascular risk, which do not require additional interventions, are highly warranted.

This study provides the first description of AASI in childhood. Our data show that AASI correlates with 24-h systolic BP and 24-h PP in children, similar to adults, as has been demonstrated by Li et al. (9). Our results confirm that AASI is increased in young hypertensive adults compared with healthy individuals. Surprisingly, children with various hypertensive diseases demonstrated elevated AASI levels alike adults when compared with normotensive subjects.

AASI was elevated in all forms of childhood hypertension including the group of children with primary hypertension. The frequent, and thus most relevant, subgroup of hypertensive children due to renal disease clearly demonstrated an elevated AASI. High AASI levels should be expected in hypertensive children with diseases, which affect the vascular structure most directly, such as in the presence of a primary or secondary coarctation of the aorta. In line with reports on pulse wave velocity measurements and supporting the assumption of AASI representing central arterial compliance, this subgroup of patients displayed the highest AASI levels $(18-20)$.

Of interest, AASI seems to correlate with the duration of the disease in children with renal disorders: children with long lasting or congenital renal disease had a higher AASI when compared with those children with shorter disease duration. This finding, although preliminary and compromised by the frequently less well-defined disease onset, supports the issue of an increased vascular damage with reduced diastolic vascular compliance during prolonged exposure to a given disease.
The PP, a sign of advanced aortic stiffness prefiguring cardiovascular risk, is age-dependent (21). Accordingly, a positive correlation of AASI with age was observed in adults, but was absent in children. An explanation might be the relatively small age range within pediatric patients. PP basically depends upon diastolic BP, indicating compromised compliance. In children, the use of PP to predict cardiovascular risk is unfavourable, because it is mainly influenced by peripheral arterial resistance and does not correlate with systolic augmentation, a marker of central arterial dysfunction and stiffness $(9,22)$. Thus, systolic BP directly correlated with AASI in all children, whereas diastolic BP was inversely correlated with AASI only in hypertensive, but not in normotensive children.

We did not identify an association between AASI and anthropometric data. Yet, in children (most of them at pubertal age), as well as in adults, a trend toward higher AASIs among males was noticed, a finding previously reported for largeartery stiffness $(23,24)$.

Recent works by Schillaci et al. (25) and Adiyaman et al. (26) showed that AASI increases in the absence of an appropriate BP dipping pattern, a finding also present in our cohorts, independent of age. Furthermore, an inappropriate dipping was found to be associated with an increased arterial stiffness $(27,28)$. Yet, daytime AASI still identified the increases seen in 24-h assessments in both groups of hypertensive individuals, children and adults, independent of their dipping status.

This study has some limitations: First, we performed the measurements with two different devices. Although a comparison of the two subgroups of hypertensive children having one or the other device showed lower 24-h systolic and diastolic BPs in the Spacelabs subgroup, the calculated PP and AASI were similar between these two subgroups, arguing for a more general applicability. In vitro testing and standardized comparisons of the devices did not yield appreciable differences, thus supporting the above assumption. Second, currently no long-term follow-up with respect to target organ damage is available in our cohort.

In conclusion, AASI, already established in adults, is easily and reliably derived from 24-h ABPM, is elevated in children with hypertensive diseases, and is correlated with the duration and the origin of hypertensive disease in childhood. Future studies should correlate the progress of end organ damages with its detection by AASI on 24-h ABPM during treatment of arterial hypertension.

\section{REFERENCES}

1. National High Blood Pressure Education Program Working Group on High Blood Pressure in Children and Adolescents 2004 The fourth report on the diagnosis, evaluation, and treatment of high blood pressure in children and adolescents. Pediatrics 114:555-576

2. Lande MB, Carson NL, Roy J, Meagher CC 2006 Effects of childhood primary hypertension on carotid intima media thickness: a matched controlled study. Hypertension 48:40-44

3. Belsha CW 1999 Ambulatory blood pressure monitoring and hypertensive targetorgan damage in children. Blood Press Monit 4:161-164

4. Blacher J, Asmar R, Djane S, London GM, Safar ME 1999 Aortic pulse wave velocity as a marker of cardiovascular risk in hypertensive patients. Hypertension 33:1111-1117

5. Domanski M, Norman J, Wolz M, Mitchell G, Pfeffer M 2001 Cardiovascular risk assessment using pulse pressure in the first national health and nutrition examination survey (NHANES I). Hypertension 38:793-797 
6. Laurent S, Boutouyrie P, Asmar R, Gautier I, Laloux B, Guize L, Ducimetiere P, Benetos A 2001 Aortic stiffness is an independent predictor of all-cause and cardiovascular mortality in hypertensive patients. Hypertension 37:1236-1241

7. Safar ME, Levy BI, Struijker-Boudier H 2003 Current perspectives on arteria stiffness and pulse pressure in hypertension and cardiovascular diseases. Circulation 107:2864-2869

8. Dolan E, Li Y, Thijs L, McCormack P, Staessen JA, O'Brien E, Stanton A 2006 Ambulatory arterial stiffness index: rationale and methodology. Blood Press Monit 11:103-105

9. Li Y, Wang JG, Dolan E, Gao PJ, Guo HF, Nawrot T, Stanton AV, Zhu DL, O'Brien E, Staessen JA 2006 Ambulatory arterial stiffness index derived from 24-hour ambulatory blood pressure monitoring. Hypertension 47:359-364

10. Dolan E, Thijs L, Li Y, Atkins N, McCormack P, McClory S, O'Brien E, Staessen JA, Stanton AV 2006 Ambulatory arterial stiffness index as a predictor of cardiovascular mortality in the Dublin Outcome Study. Hypertension 47:365-370

11. Leoncini G, Ratto E, Viazzi F, Vaccaro V, Parodi A, Falqui V, Conti N, Tomolillo C, Deferrari G, Pontremoli R 2006 Increased ambulatory arterial stiffness index is associated with target organ damage in primary hypertension. Hypertension 48:397403

12. Leoncini G, Ratto E, Viazzi F, Vaccaro V, Parodi A, Falqui V, Conti N, Tomolillo C, Deferrari G, Pontremoli R 2007 Metabolic syndrome and ambulatory arterial stiffness index in non-diabetic patients with primary hypertension. J Hum Hypertens 21:802-807

13. Wuhl E, Witte K, Soergel M, Mehls O, Schaefer F 2002 Distribution of 24-h ambulatory blood pressure in children: normalized reference values and role of body dimensions. J Hypertens 20:1995-2007

14. Soergel M, Kirschstein M, Busch C, Danne T, Gellermann J, Holl R, Krull F, Reichert H, Reusz GS, Rascher W 1997 Oscillometric twenty-four-hour ambulatory blood pressure values in healthy children and adolescents: a multicenter trial including 1141 subjects. J Pediatr 130:178-184

15. Cole TJ, Bellizzi MC, Flegal KM, Dietz WH 2000 Establishing a standard definition for child overweight and obesity worldwide: international survey. BMJ 320:12401243
16. Weber T, Auer J, O’Rourke MF, Kvas E, Lassnig E, Berent R, Eber B 2004 Arterial stiffness, wave reflections, and the risk of coronary artery disease. Circulation 109:184-189

17. Aggoun Y, Szezepanski I, Bonnet D 2005 Noninvasive assessment of arterial stiffness and risk of atherosclerotic events in children. Pediatr Res 58:173-178

18. de Divitiis M, Pilla C, Kattenhorn M, Zadinello M, Donald A, Leeson P, Wallace S, Redington A, Deanfield JE 2001 Vascular dysfunction after repair of coarctation of the aorta: impact of early surgery. Circulation 104:I165-I170

19. Mersich B, Studinger P, Lenard Z, Kadar K, Kollai M 2006 Transposition of great arteries is associated with increased carotid artery stiffness. Hypertension 47:11971202

20. Aggoun Y, Sidi D, Bonnet D 2001 Arterial dysfunction after treatment of coarctation of the aorta. Arch Mal Coeur Vaiss 94:785-789

21. Franklin SS, Larson MG, Khan SA, Wong ND, Leip EP, Kannel WB, Levy D 2001 Does the relation of blood pressure to coronary heart disease risk change with aging? The Framingham Heart Study. Circulation 103:1245-1249

22. Benetos A, Lacolley P 2006 From 24-hour blood pressure measurements to arterial stiffness: a valid short cut? Hypertension 47:327-328

23. Ahimastos AA, Formosa M, Dart AM, Kingwell BA 2003 Gender differences in large artery stiffness pre-and post puberty. J Clin Endocrinol Metab 88:5375-5380

24. Hlaing WM, Prineas RJ 2006 Arterial stiffness variations by gender in AfricanAmerican and Caucasian children. J Natl Med Assoc 98:181-189

25. Schillaci G, Parati G, Pirro M, Pucci G, Mannarino MR, Sperandini L, Mannarino E 2007 Ambulatory arterial stiffness index is not a specific marker of reduced arterial compliance. Hypertension 49:986-991

26. Adiyaman A, Boggia J, Li Y, Wang JG, O'Brien E, Richart T, Thijs L, Staessen JA 2007 Dipping deeper into the ambulatory arterial stiffness index. Hypertension 50:e59

27. Asar R, Scuteri A, Topouchian J, Brisac AM, Maldonado J, Cloarec L, Safar M 1996 Arterial distensibility and circadian blood pressure variability. Blood Press Monit 1:333-338

28. Jerrard-Dunne P, Mahmud A, Feely J 2007 Circadian blood pressure variation: relationship between dipper status and measures of arterial stiffness. J Hypertens 25:1233-1239 